\title{
Energetic and Financial Comparison between a 1-Stage Absorption Chiller Driven by FPC and a 2-Stage Absorption Chiller Driven by PTC
}

\author{
Evangelos Bellos, Christos Tzivanidis, Nikolaos Zervas, Georgios Mitsopoulos, Kimon A. Antonopoulos \\ National Technical University of Athens/ School of Mechanical Engineering \\ Heroon Polytechniou 9, Zografou-Athens, Greece \\ bellose@central.ntua.gr; ctzivan@central.ntua.gr; mc09003@central.ntua.gr; gdmitsopoulos@central.ntua.gr; \\ kanton@central.ntua.gr
}

\begin{abstract}
Solar energy utilization is very important for our society which faces the global warming problem and the increase in fossil fuels price. A common application of solar energy is the solar-cooling with a sorption machine. In this study, two solar cooling absorption systems are investigated for a large building in Athens. More specifically, the first system uses flat plate collectors (FPC) coupled with a 1-stage absorption chiller operating with $\mathrm{Li}-\mathrm{Br} / \mathrm{H}_{2} \mathrm{O}$ and the second uses parabolic trough collectors (PTC) coupled with a 2-stage absorption chiller operating with $\mathrm{Li}-\mathrm{Br} / \mathrm{H}_{2} \mathrm{O}$. The first system operates in low temperature levels with a coefficient of performance (COP) about 0.6, while the other system operates with a double COP but higher temperature is necessary. A financial evaluation is important in order to determine the most attractive system for this study case. The simulation tool is TRNSYS 16, which is a powerful energy tool and simulates easily large and combined systems. The final results show that both systems are sustainable with the system with PTC to be the most suitable. More specifically, the optimum case in the FPC-system leads to $1400 \mathrm{~m}^{2}$ collecting area with a net present cost $709 \mathrm{k} €$, while in the PTC-system, a $1000 \mathrm{~m}^{2}$ collecting area leads to a net present cost $429 \mathrm{k} €$.
\end{abstract}

Keywords: Absorption chiller, solar cooling, FPC, PTC, air-conditioning, TRNSYS

\section{Introduction}

The role of solar energy gains more and more attention today due to the increase of the worldwide energy consumption [1], the fossil fuels crisis and its renewable characteristics. Energy from the sun is thereby cheaper in many cases and reduces $\mathrm{CO}_{2}$ emissions [2-3]. Solar energy can have multiple uses: cooling, heating, industrial heating, desalination, poly-generation (combination with biomass) [4-6]. Solar cooling is an innovative, promising alternative to reduce the peak energy consumption (electrical energy) generated by excessive use of vapor compression systems, especially during summer months. The attractiveness of utilizing solar energy is mainly due to the fact that demand and supply of energy coincide. In fact, cooling is required when the solar radiation is abundantly available. Furthermore, great majority of solar techniques employs harmless working fluids. Especially in Greece, solar cooling systems have a great potential due to the high irradiation level: The annual average energy for global horizontal irradiance is $1400-1500 \mathrm{kWh} \mathrm{m}^{-}$ ${ }^{2}$ in Northern Greece and up to $1900 \mathrm{kWh} \mathrm{m}^{-2}$ in Southern Peloponnese, Crete and the islands while there, during summer months, the monthly solar energy values exceed $250 \mathrm{kWh} \mathrm{m}^{-2}$ [7].

Solar cooling technologies demonstrate a significant growth rate in European commercial and residential buildings. Through the EU SACE (Solar Air Conditioning in Europe) project, Balaras et al. [8] surveyed and analyzed over 50 solarpowered cooling projects, showed that, for southern European and Mediterranean areas, solar assisted cooling systems can lead to primary energy savings in the range of 40-50\% and provided useful guidelines to encourage further applications of these technologies. A. Allouhi et al. [9] studied sorption technologies in different climatic zones of Europe and showed that adsorption technology resulted in energy savings ranging from 29 to $55 \%$, absorption technology from 25 to $52 \%$ and desiccant cooling systems from 16 to $56 \%$. The double effect absorption technology driven by parabolic trough collectors using Lithium Bromide/water as a working pair has the maximal coefficient of performance (1.1-1.4). In general, absorption chillers are appreciated because of their easy implementation and silent operation. Moreover, thermal driven systems have the advantage to serve in heating and hot water production during periods when cooling is not requested. For these reasons, many studies have been made in this area in order to analyze and optimize the operation of thermal driven chillers in various operating conditions. Abdul Ghafoor and Anjum Munir [10] marked that the COP of absorption chillers 
lies between 0.6-0.8 for generator inlet temperature between $70-100^{\circ} \mathrm{C}$ while the COP of adsorption chillers lies in the range of 0.2-0.6 with lower inlet temperatures between $45-65^{\circ} \mathrm{C}$. They also noted that the ratio of storage volume to collector area ranges from 5 to $1301 / \mathrm{m}^{2}$ and depends on the system scale. D.S. Kim and C.A. Infante Ferreira [11] showed that absorption and adsorption systems are the best solution compared to solar thermo-mechanical and solar photovoltaic systems. Z.S. Lu and R.Z. Wang [12] integrated an evacuated tube solar collector with a silica gel-water adsorption chiller, a high efficiency CPC solar collector with a single-effect $\mathrm{LiBr} / \mathrm{H}_{2} \mathrm{O}$ absorption chiller and a PTC solar collector with a double-effect $\mathrm{LiBr} / \mathrm{H}_{2} \mathrm{O}$ absorption chiller and analyzed their performances. Their solar COPs were 0.15, 0.24 and 0.5 respectively, proving the latter system the most attractive. HaiQuan Sun et al. [13] studied a hybrid system capable of combining solar absorption cooling in single effect and gas fired absorption cooling in double effect chiller, which reduces the gas consumption by half. Roland Winston et al. [14] combined non-tracking external Compound Parabolic Collectors (XCPC) with a double-effect absorption chiller and showed that, with a temperature range between $160-200^{\circ} \mathrm{C}$, the system collects solar energy with an average daily Solar COP of 0.367. Christine Weber et al. [15] studied the use of a linear concentrating Fresnel collector combined with two absorption chillers at temperatures up to $200^{\circ} \mathrm{C}$ and showed that, for good operating conditions, the thermal system EER of the chiller was 0.8. Carolina Marugan-Cruz et al. [16] analyzed the case of a circular field of heliostats focusing at an external receiver of $120 \mathrm{MW}_{\text {th }}$, producing steam for eight double effect absorption chillers, supplying, that way, for a population of 90000 people, $47 \%$ of the total cooling load.

In this study, two solar driven absorption systems are compared energetically and financially in order to predict the most suitable for Athens. The first system uses flat plat collectors (FPC) coupled with a single absorption chiller operating with $\mathrm{Li}-\mathrm{Br} / \mathrm{H}_{2} \mathrm{O}$ and the second uses Parabolic Trough Collectors (PTC) coupled with a double absorption chiller operating with $\mathrm{Li}-\mathrm{Br} / \mathrm{H}_{2} \mathrm{O}$. The first system has a lower capital cost, but operates in lower temperature levels which leads a lower COP, compared to the second system. So a financial evaluation is necessary to evaluate these technologies. The analysis is made with the commercial software TRNSYS 16 which is a useful tool for energetic simulations.

\section{Examined system}

The examined system consists of the building and the cooling system. At first, the building is analyzed and presented and consequently the two cooling systems.

\subsection{Examined Building}

Solar cooling applications are applied to buildings with high cooling loads. For this reason a large building is examined in this study. The dimensions of this building are $40 \times 40 \times 3\left(\mathrm{~m}^{3}\right)$ and the maximum cooling load is about $120 \mathrm{~kW}$. The desired operation temperature was set at $26^{\circ} \mathrm{C}$ in order to make preferable thermal comfort conditions inside the building. The next table gives the monthly loads of the building, calculated by TRNSYS. These are the minimum theoretical cooling loads for keeping the indoor temperature lower than $26^{\circ} \mathrm{C}$.

Table 1: Monthly cooling Loads of the examined Building.

\begin{tabular}{|l|l|l|l|l|l|l|l|}
\hline Month & May & June & July & August & September & October & Total \\
\hline $\mathrm{Q}_{\text {cool }}(\mathrm{kWh})$ & 41630 & 48990 & 56110 & 55800 & 46130 & 37820 & 286500 \\
\hline
\end{tabular}

The total cooling load is $286500 \mathrm{kWh}$ and should be covered by the absorption chiller. The next table gives extra information about the building. More specifically, the windows of the building are specified, the internal loads are presented and other important information are given.

The building consists of 4 outer similar walls and a roof (without internal walls). The roof of the building has three layers; the outer is cement with $15 \mathrm{~cm}$ thickness, the intermediate is insulation of $10 \mathrm{~cm}$ thickness and the inner plaster of $1.5 \mathrm{~cm}$ thickness with a U-value equal to $0.36 \mathrm{~W} / \mathrm{m}^{2} \mathrm{~K}$. The outer wall is a 5 layer wall with the following materials: $1.5 \mathrm{~cm}$ plaster, $10 \mathrm{~cm}$ brick, $5 \mathrm{~cm}$ insulation, $10 \mathrm{~cm}$ brick and $1.5 \mathrm{~cm}$ plaster with a $\mathrm{U}$-value equal to $0.6 \mathrm{~W} / \mathrm{m}^{2} \mathrm{~K}$. The ground has $\mathrm{U}$ Value about $0.31 \mathrm{~W} / \mathrm{m}^{2} \mathrm{~K}$. 
Table 2: Building simulation parameters.

\begin{tabular}{|l|l|l|l|}
\hline Parameter & Value & Parameter & Value \\
\hline City & Athens & Specific gains (equipment) & $14 \mathrm{~W} / \mathrm{m}^{2} \mathrm{~K}$ \\
\hline Floor area & $1600 \mathrm{~m}^{2}$ & Occupants density & $0.1 \mathrm{person} / \mathrm{m}^{2}$ \\
\hline Height & $3 \mathrm{~m}$ & Specific light & $10 \mathrm{~W} / \mathrm{m}^{2}$ \\
\hline East window & $36 \mathrm{~m}^{2}$ & Infiltration rate & 1 change per hour \\
\hline West window & $36 \mathrm{~m}^{2}$ & Thermal Capacitance & $11520 \mathrm{~kJ} / \mathrm{K}$ \\
\hline South window & $48 \mathrm{~m}^{2}$ & Insulation conductivity & $\mathrm{k}=0.04 \mathrm{~W} / \mathrm{mK}$ \\
\hline Shading coefficient & $60 \%$ & $\mathrm{~h}_{\text {out }}$ & $17.8 \mathrm{~W} / \mathrm{m}^{2} \mathrm{~K}$ \\
\hline Window U-value & $1.4 \mathrm{~W} / \mathrm{m}^{2} \mathrm{~K}$ & $\mathrm{~h}_{\text {in }}$ & $3.1 \mathrm{~W} / \mathrm{m}^{2} \mathrm{~K}$ \\
\hline
\end{tabular}

\subsection{Solar Cooling System}

In this paragraph the solar cooling systems are described, where the design parameters are given in every case. The next figure shows the two systems.
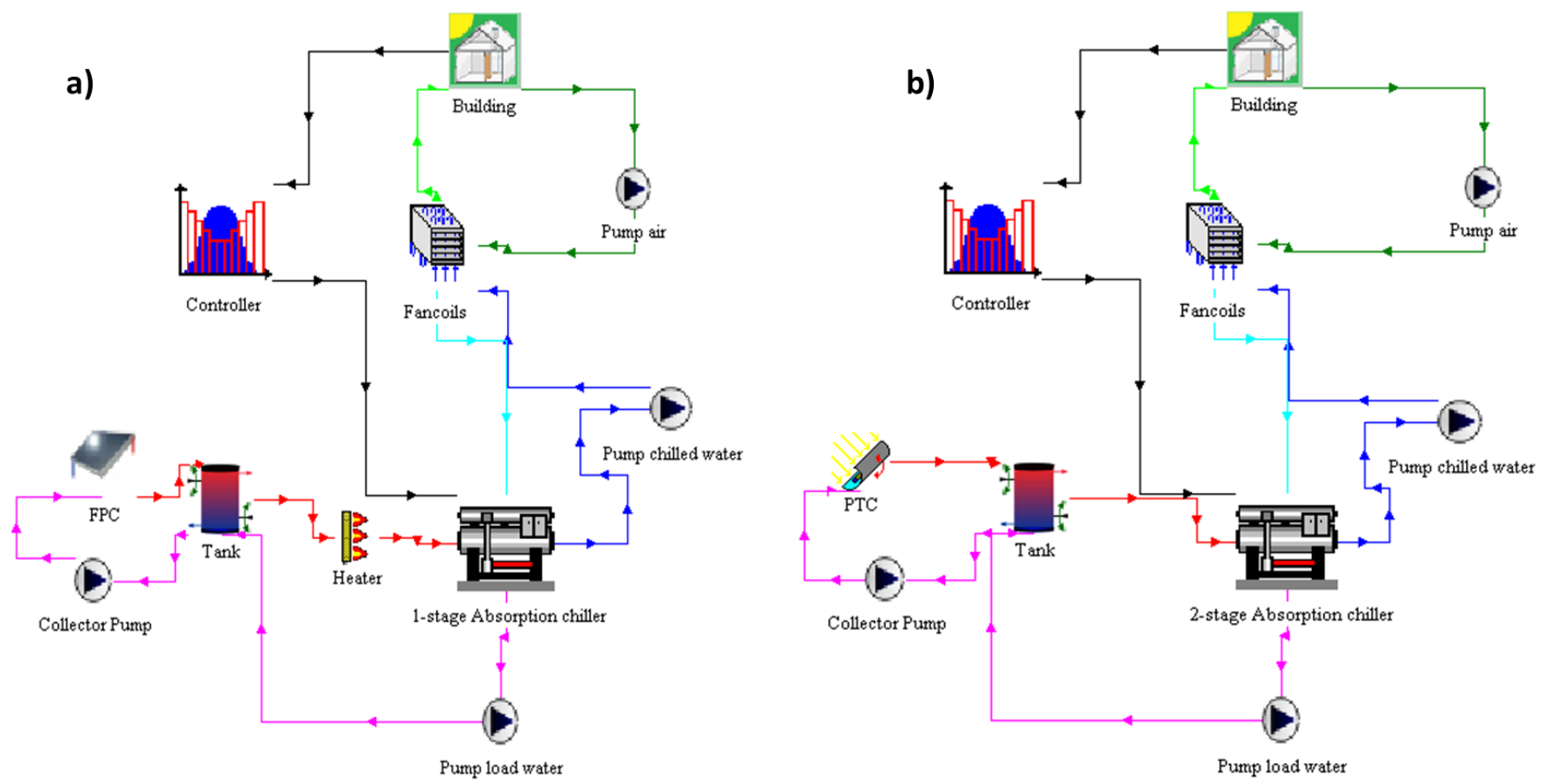

Fig. 1: Examined systems a) FPC with 1-stage absorption chiller, b) PTC with 2-stage absorption chiller.

Figure 1 presents the two examined systems. In every system the solar collectors heat the working fluid and store it to the storage tank. The stored water drives the absorption chiller, when the cooling load is needed. In the case that the working fluid has not the necessary temperature to drive the chiller, the extra heater operates and additionally heats the working fluid. In the case of FPC, the operating temperature levels is low, so the working fluid is water, but in the case of PTC the temperature levels are greater than $100^{\circ} \mathrm{C}$ so thermal oil used as working fluid. The properties of the thermal oil are presented in table 4. More specifically, the desired operating temperature for the 1 -stage chiller is $80^{\circ} \mathrm{C}$ and for the 2 stage $140^{\circ} \mathrm{C}$, while the nominal COP are 0.6 and 1.2 respectively. It is important to state that the chillers operate when the temperature in their inlet is greater than the minimum limit. The chiller produce chilled water at $10^{\circ} \mathrm{C}$ which flows to the fan-coils cooling the air. A control system is used in order to determine the operation of the chiller. Circulators are placed in every loop of the above systems in order to adjust the mass flow rates, which are presented in tables 3 and 4 . The storage tank has been modelled with 5 mix-zones in order to correspond with reality and exchanges heat with the environment with a heat loss coefficient equal to $0.7 \mathrm{~W} / \mathrm{m}^{2} \mathrm{~K}$ (convection \& radiation). For the PTC system, a 1-axis tracking system is 
necessary in order for the collectors to follow the sun during the day. The Parabolic Trough Collectors are placed with their axis in North-South direction, tracking the sun in the East-West direction, during the day. That way the optical efficiency increases drastically by adding an extra cost to the system. Moreover, it is essential to state that PTC utilizes only the beam radiation of the sun, because they are imaging concentrating collectors. The following tables give extra information about the two systems. Table 3 presents the FPC system and table 4 the PTC system.

Table 3: Parameters of the FPC system with the 1-stage absorption chiller.

\begin{tabular}{|l|l|l|l|}
\hline Parameters & Value & Parameters & Value \\
\hline COP & 0.6 & Collector water mass flow rate & $10 \mathrm{~kg} / \mathrm{s}$ \\
\hline $\mathrm{T}_{\min }$ & $80^{\circ} \mathrm{C}$ & Mass flowrate to chiller & $8 \mathrm{~kg} / \mathrm{s}$ \\
\hline Collector operation hours & $9: 00-18: 00$ & Chilled water mas flowrate & $2.1 \mathrm{~kg} / \mathrm{s}$ \\
\hline Azimuth collector angle & $0^{\circ}$ & Cold air mas flowrate & $10 \mathrm{~kg} / \mathrm{s}$ \\
\hline Collector slope & $45^{\circ}$ & Chiller power & $200 \mathrm{~kW}$ \\
\hline Intercept efficiency & 0.8 & Heater Power & $200 \mathrm{~kW}$ \\
\hline Efficiency slope & 3.61 & Tank loss coefficient & $0.7 \mathrm{~W} / \mathrm{m}^{2} \mathrm{~K}$ \\
\hline
\end{tabular}

Table 4: Parameters of the PTC system with the 2-stage absorption chiller.

\begin{tabular}{|l|l|l|l|}
\hline Parameters & Value & Parameters & Value \\
\hline COP & 1.2 & Collector water mass flow rate & $14 \mathrm{~kg} / \mathrm{s}$ \\
\hline $\mathrm{T}_{\text {min }}$ & $140{ }^{\circ} \mathrm{C}$ & Mass flowrate to chiller & $2 \mathrm{~kg} / \mathrm{s}$ \\
\hline Tank loss coefficient & $0.7 \mathrm{~W} / \mathrm{m}^{2} \mathrm{~K}$ & Chilled water mas flowrate & $2.1 \mathrm{~kg} / \mathrm{s}$ \\
\hline Tracking system & 1 -axis & Cold air mas flowrate & $10 \mathrm{~kg} / \mathrm{s}$ \\
\hline Collector operation hours & $9: 00-18: 00$ & Chiller power & $200 \mathrm{~kW}$ \\
\hline Concertation ratio & 35 & Heater Power & $200 \mathrm{~kW}$ \\
\hline Intercept efficiency & 0.8 & Oil density & $950 \mathrm{~kg} / \mathrm{m}^{3}$ \\
\hline Efficiency slope & 0.56 & Oil heat capacity & $2100 \mathrm{~kJ} / \mathrm{kg} \mathrm{K}$ \\
\hline
\end{tabular}

\section{Results} system.

In this section the energetic and financial results of the simulations are presented in order to predict the optimum

\subsection{Energetic analysis}

The goal of this analysis is to determine the financial optimum solution. The first step before the financial evaluation is the energetic analysis. Two are the main parameters of every examined system, the collecting area and the storage tank volume. For every collecting area there is an optimum volume for the storage tank. A great tank stores more working fluid, but leads to a lower mean operation temperature. Also a great tank increases the capital cost of the investment. For this reason the optimization of this parameter is crucial for this study. By testing different volumes of storage tank in every case, the optimum values are calculated and are presented in Figure 2. The optimum tank is the one which leads to greater solar coverage.

It is obvious that a greater collecting area requires a greater tank, which is acceptable. In the case of PTC, the optimum tank volume increases linearly with the collecting area, but in the case of FPC, it increases linearly up to $3000 \mathrm{~m}^{2}$ and after this point the slope of the curve is getting lower. In other words, after a certain point the increase in the storage tank size has not great effect on the system performance. The next figure presents the solar coverage for the two cases as a function of collecting area. In every case, the optimum storage tank volume is used. 


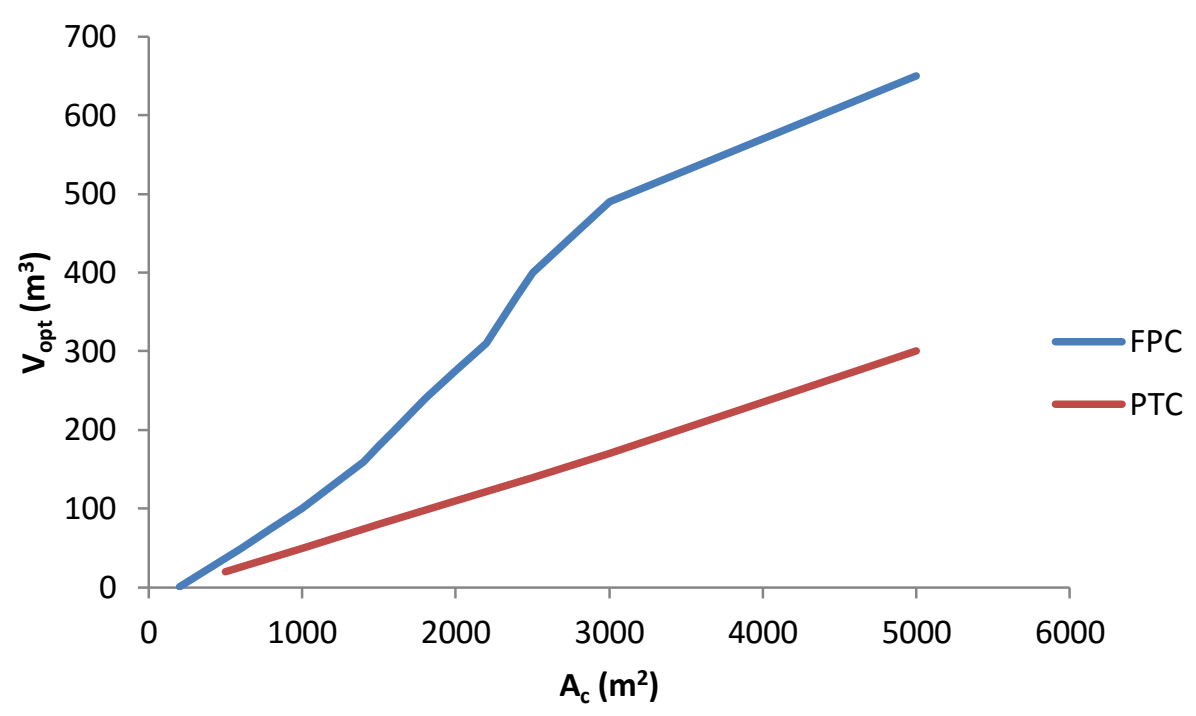

Fig. 2: Optimum storage tank volume for different collecting areas. The blue line stands for the FPC system and the red for the PTC system.

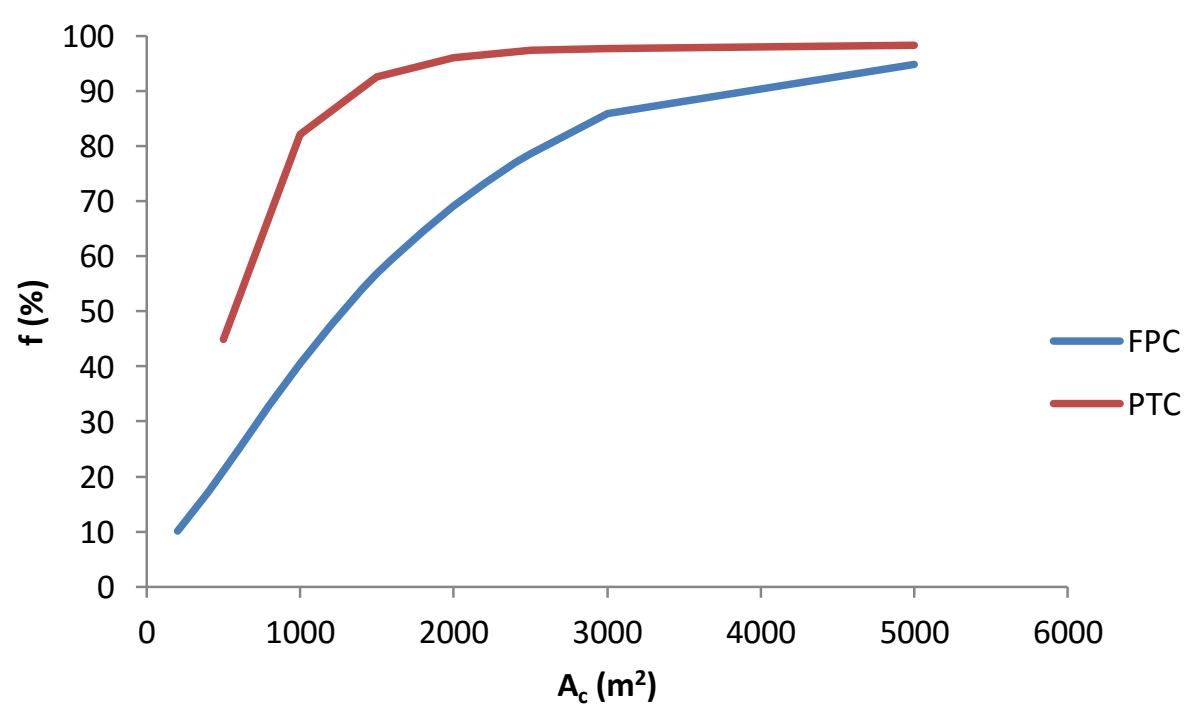

Fig. 3: Solar coverage for different collecting areas. The blue line for the FPC system and the red for the PTC system.

Figure 3 shows that greater collecting area increases the solar coverage. The solar coverage is the proportion of the energy need that is covered by the sun. In other words, more solar collector captures greater amounts of solar energy and reduces the auxiliary electrical energy by the heater. For the PTC system, after the point of $1000 \mathrm{~m}^{2}$, the curve tends to be equal to $100 \%$. The solar coverage for the FPC system is the lowest one since an equal collecting area of FPC gives smaller amounts of useful energy. The solar coverage in FPC system is increasing with a high rate until $3000 \mathrm{~m}^{2}$ and after with a lower rate. By considering only the energetic factors, parabolic collectors coupled with a 2-stage chiller are the optimum solution, but they have a greater capital cost. Thus, the financial evaluation in the following paragraph will lead to the final decision between the two examined systems. 


\subsection{Financial analysis}

The first and most important step in the financial evaluation is to predict the cost of every device. Table 5 gives the specific costs for the main parameters of the two systems. The values are realistic regarding the examined scale.

Table 5: Parameters of the PTC.

\begin{tabular}{|l|l|}
\hline Device & Specific cost \\
\hline 1-stage absorption chiller & $268 € / \mathrm{kW}[\mathbf{1 7}]$ \\
\hline 2-stage absorption chiller & $279 € / \mathrm{kW}[\mathbf{1 7}]$ \\
\hline FPC & $175 € / \mathrm{m}^{2}[\mathbf{1 8}]$ \\
\hline PTC & $250 € / \mathrm{m}^{2}[\mathbf{1 9}]$ \\
\hline Circulator & $700 € \quad[\mathbf{2 0}]$ \\
\hline Electrical Heater & $85 € / \mathrm{kW}[\mathbf{2 0}]$ \\
\hline Tank & $150 € / \mathrm{m}^{3}[\mathbf{2 0}]$ \\
\hline etc costs & $250 € / \mathrm{kW}[\mathbf{2 0}]$ \\
\hline
\end{tabular}

It is important to state that the extra heat is produced by an electrical heater which leads to electrical consumption. The 2-stage chiller is more expensive than the 1-stage, which is logical, since it is more complicated. Moreover, the PTCs are about $40 \%$ more expensive than the FPC, because their construction should be more deliberate. The thermal energy cost was taken equal to electrical cost $(0.12 € / \mathrm{kWh})$, because the heater is electrical in this case. In every case the cost of every technology is calculated and the cheaper case is the optimum. More specifically, the net present value or the net present cost for a 20 year period is calculated in every case and compared with the other cases. The discount factor was selected to be 5\%. The next figures 4,5 give the Net Present Value (NPV) and the solar coverage for the FPC-system and PTC-system respectively, for different collecting area values.

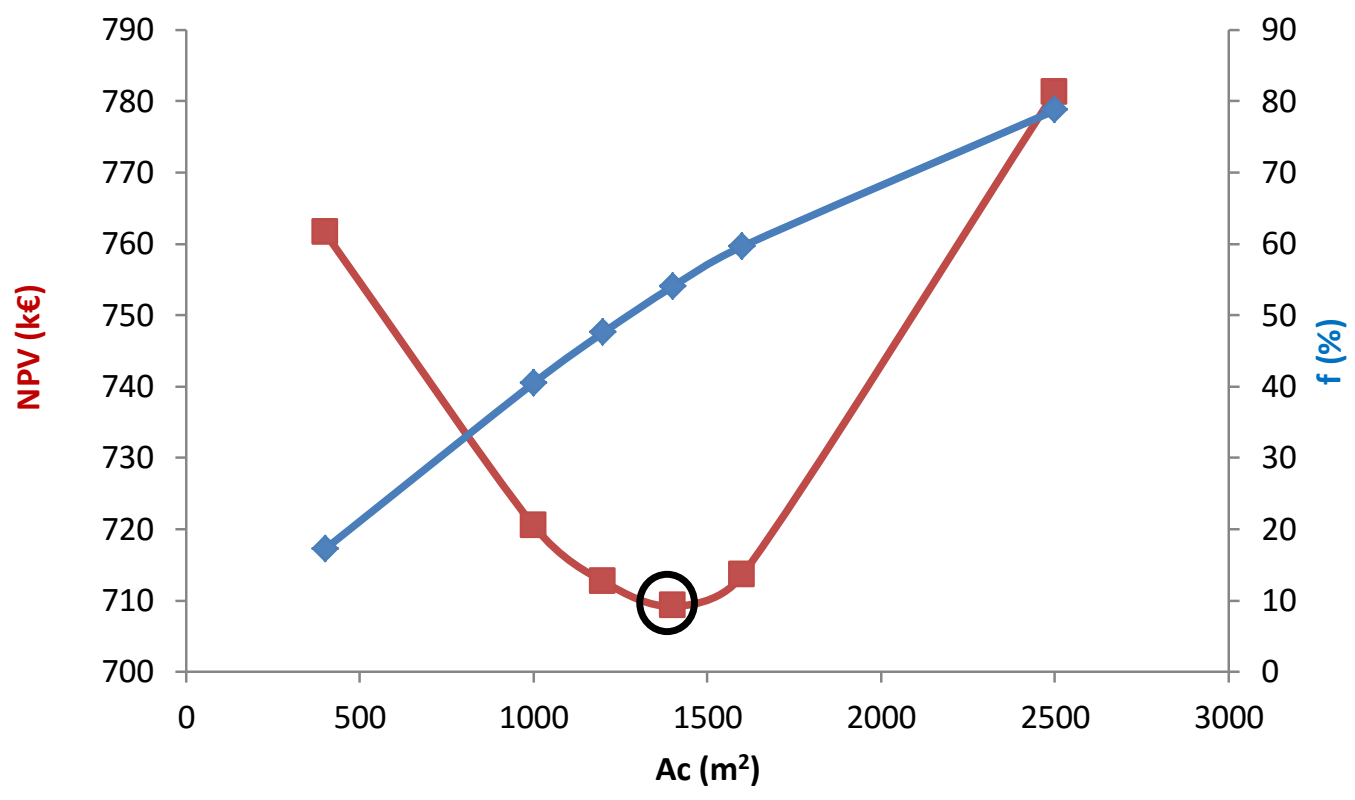

Fig. 4: NPV and solar coverage of FPC-system. 


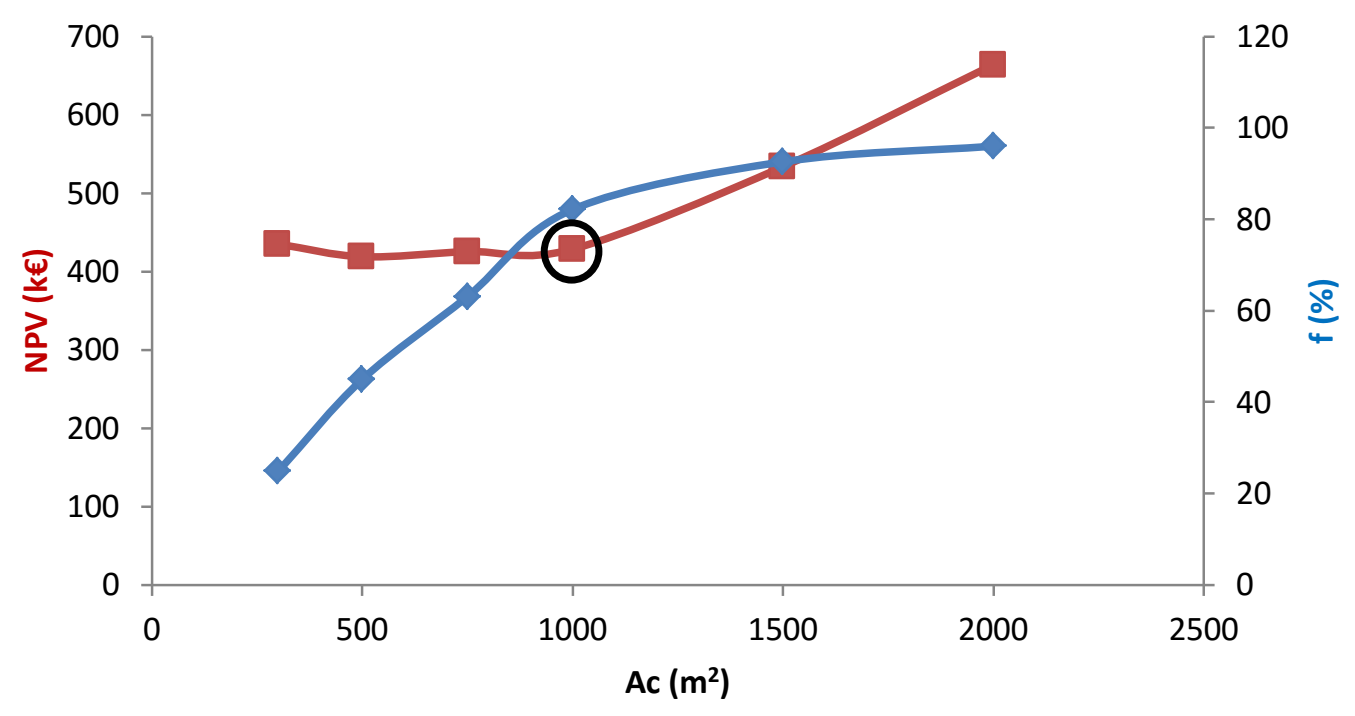

Fig. 5: NPV and solar coverage of PTC-system.

Figure 4 shows that the optimum solution is for $1400 \mathrm{~m}^{2}$ collecting area with a NPV of $709 \mathrm{k} €$, where the minimum NPV and a satisfying coverage is observed. In figure 5, the NPV is roughly speaking constant until $1000 \mathrm{~m}^{2}$ and after this value it increases. So the value $1000 \mathrm{~m}^{2}$ is selected as the optimum one because in this case the solar coverage is greater which means greater solar energy utilization. The next table gives all final results of the two optimum solutions.

Table 6: Final results of optimum cases.

\begin{tabular}{|l|l|l|l|l|l|}
\hline CASE & $\mathbf{A}_{\mathbf{c}}\left(\mathbf{m}^{\mathbf{2}}\right)$ & $\mathbf{V}\left(\mathbf{m}^{\mathbf{3}}\right)$ & $\begin{array}{l}\mathbf{Q}_{\text {heater }} \\
(\mathbf{k W h})\end{array}$ & $\mathbf{f ( \% )}$ & NPV (k€) \\
\hline FPC & 1400 & 160 & 223367 & 54.0 & 709 \\
\hline PTC & 1000 & 50 & 42588 & 82.2 & 429 \\
\hline
\end{tabular}

As we can see, the NPV in the case of PTC-system is lower than in the case of FPC-system. For this reason, the use of parabolic trough collectors with a 2-stage absorption chiller is the financial optimum choice for this study case.

\section{Conclusions}

In this study, two solar driven absorption systems for cooling are investigated and compared energetically and financially. In the first system, a single-stage absorption chiller is driven by heat from flat plate collectors and in the second, a double-stage absorption chiller is driven by heat from parabolic trough. In other words, the first system is a low efficiency system which operates with cheaper and simpler devices, while the other demonstrates a better performance but uses specified machines. The main parameters of the optimization method that was followed were the storage tank volume and the collecting area.

The optimum volume of storage tank increases for higher collecting areas. In the case of PTC system the dependency is linearly, while in the FPC-system the curve is separated in two regions because after a critical point a greater tank does not improve the system performance significantly. The solar coverage is increasing with higher collecting area, and after a critical point it reaches the maximum possible value for every system. The PTC-system leads to greater solar coverage values, because the concentrated collectors have greater thermal efficiency than the flat plate collectors.

In the financial evaluation, PTC was proved as the optimum system with a net present cost of $429 \mathrm{k} €$, while the FPCsystem has a net present cost of $709 \mathrm{k} €$. The optimum collecting area is lower for the PTC system $\left(1000 \mathrm{~m}^{2}\right)$ than the FPCsystem $\left(1400 \mathrm{~m}^{2}\right)$ which balances its greater specific cost. So the greater COP of the PTC system is the reason for their best performance. 


\section{References}

[1] E. Bellos, C. Tzivanidis, and K. A. Antonopoulos, "Comparison of two solar driven absorption chillers for airconditioning in Greece," in Proceedings of the 6th International Conference on Experiments/Process/System Modelling/Simulation/Optimization, Athens, Greece, 2015.

[2] Z. Xingjuan, S. Bojie, B. Qingyuan, and Y. Chunxin, "Performance analysis on a new type of solar air conditioning system," Energy and Buildings, vol. 60, pp. 280-285, 2013.

[3] K. F. Fong, C. K. Lee, Z. Lin, T. T. Chow, and L. S. Chan, "Application potential of solar air-conditioning systems for displacement ventilation," Energy and Buildings, vol. 43, pp. 2068-2076, 2011.

[4] D. N. Nkwetta, M. Smyth, A. Zacharopoulos, and T. Hyde, "Optical evaluation and analysis of an internal lowconcentrated evacuated tube heat pipe solar collector for powering solar air conditioning systems," Renewable Energy, vol. 39, pp. 65-70, 2012.

[5] N. S. Suresh, N. C. Thirumalai, B. S. Rao, and M. A. Ramaswamy, "Methodology for sizing the solar field for parabolic trough technology with thermal storage and hybridization," Solar Energy, vol. 110, pp. 247-259, 2014.

[6] U. Sahoo, R. Kumar, P. C. Pant, and R. Chaudhury, "Scope and sustainability of hybrid solar-biomass power plant with cooling, desalination in polygeneration process in India," Renewable and Sustainable Energy Reviews, vol. 51, pp. 304-316, 2015.

[7] E. Nikitidou, A. Kazantzidis, P. Tzoumanikas, V. Salamalikis, and A. F. Bais, "Retrieval of surface solar irradiance, based on satellite-derived cloud information, in Greece," Energy, vol. 90, no. 1, pp. 776-783, 2015.

[8] C. A. Balaras, G. Grossman, H. M. Henning, C. A. I. Ferreira, E. Podesser, L. Wang, and E. Wiemken, "Solar air conditioning in Europe-an overview," Renewable and Sustainable Energy Reviews, vol. 11, no. 2, pp. 299-314, 2007.

[9] A. Allouhi, T. Kousksou, A. Jamil, P. Bruel, Y. Mourad, and Y. Zeraouli, "Solar driven cooling systems: An updated review," Renewable and Sustainable Energy Reviews, vol. 44, pp. 159-181, 2015.

[10] A. Ghafoor and A. Munir, "Worldwide overview of solar thermal cooling technologies," Renewable and Sustainable Energy Reviews, vol. 43, pp. 763-774, 2015.

[11] D. S. Kim and C. A. I. Ferreira, "Solar refrigeration options - a state-of-the-art review," International Journal of Refrigeration, vol. 31, no. 1, pp. 3-15, 2008.

[12] Z. S. Lu and R. Z. Wang, "Experimental performance investigation of small solar air-conditioning systems with different kinds of collectors and chillers," Solar Energy, vol. 110, pp. 7-14, 2014.

[13] H. Q. Sun, Z. Y. Xu, H. B. Wang, and R. Z. Wang, "A Solar/gas Fired Absorption System for Cooling and Heating in a Commercial Building," Energy Procedia, vol. 70, pp. 518-528, 2015.

[14] R. Winston, L. Jiang, and B. Widyolar, "Performance of a 23KW Solar Thermal Cooling System Employing a Double Effect Absorption Chiller and Thermodynamically Efficient Non-tracking Concentrators," Energy Procedia, vol. 48, pp. 1036-1046, 2014.

[15] C. Weber, M. Berger, F. Mehling, A. Heinrich, and T. Núñez, "Solar cooling with water-ammonia absorption chillers and concentrating solar collector - Operational experience," International Journal of Refrigeration, vol. 39, pp. 57-76, 2014.

[16] C. Marugán-Cruz, S. Sánchez-Delgado, M. R. Rodríguez-Sánchez, M. Venegas, and D. Santana, "District cooling network connected to a solar power tower," Applied Thermal Engineering, vol. 79, pp. 174-183, 2015.

[17] Global Quality Solutions, BROAD X Absorption Chiller Model Selection \& Design Manual, 2008.

[18] S. Karellas, K. Terzis, and D. Manolakos, "Investigation of an autonomous hybrid solar thermal ORC-PV RO desalination system. The Chalki island case," Renewable Energy, vol. 36, no. 2, pp. 583-590, 2011. 